\title{
Can we prevent or treat multiple sclerosis by individualised vitamin D supply?
}

Jan Dörr ${ }^{1,2^{*}}$, Andrea Döring ${ }^{1,2,3}$ and Friedemann Paul ${ }^{1,2}$

\begin{abstract}
Apart from its principal role in bone metabolism and calcium homeostasis, vitamin D has been attributed additional effects including an immunomodulatory, anti-inflammatory, and possibly even neuroprotective capacity which implicates a possible role of vitamin D in autoimmune diseases like multiple sclerosis (MS). Indeed, several lines of evidence including epidemiologic, preclinical, and clinical data suggest that reduced vitamin D levels and/or dysregulation of vitamin D homeostasis is a risk factor for the development of multiple sclerosis on the one hand, and that vitamin $D$ serum levels are inversely associated with disease activity and progression on the other hand. However, these data are not undisputable, and many questions regarding the preventive and therapeutic capacity of vitamin D in multiple sclerosis remain to be answered. In particular, available clinical data derived from interventional trials using vitamin D supplementation as a therapeutic approach in MS are inconclusive and partly contradictory. In this review, we summarise and critically evaluate the existing data on the possible link between vitamin $D$ and multiple sclerosis in light of the crucial question whether optimization of vitamin D status may impact the risk and/or the course of multiple sclerosis.
\end{abstract}

Keywords: Multiple sclerosis, Vitamin D, Cholecalciferol, Prevention, Therapy, Risk factor, Supplementation, Personalised medicine, Targeted prevention, Tailored therapy

\section{Review}

\section{Multiple sclerosis: background information}

Multiple sclerosis (MS) is the most common chronic inflammatory disease of the central nervous system (CNS) in young adults in Western countries and often leads to early disability and retirement [1]. Typical clinical manifestations are optic neuritis, central paralysis, sensory disturbances, and difficulties in coordination and balance, as well as cognitive dysfunction, fatigue, and sleep disorders [1-3]. The initial course is usually relapsing-remitting, but after several years, the disease tends to convert into a secondary progressive form. A primary progressive course also exists but is much less common. It is estimated that 2.5 million people suffer from MS worldwide, and as in most autoimmune disorders, there is an obvious female preponderance of approximately 3 to 4:1 [1,4]. Importantly, most female patients are affected in their child-

\footnotetext{
*Correspondence: jan-markus.doerr@charite.de

'NeuroCure Clinical Research Center, Charité - Universitätsmedizin Berlin, Charitéplatz 1, Berlin 10117, Germany

${ }^{2}$ Clinical and Experimental Research Center for Multiple Sclerosis, Charité Universitätsmedizin Berlin, Berlin, Germany

Full list of author information is available at the end of the article
}

bearing age which may have fundamental consequences for family planning [5]. The cause of MS is not yet clear. Several genetic and environmental factors have been isolated to contribute to the risk of MS, among them vitamin $\mathrm{D}$ (VD) status, but the individual significance of each factor is not yet clear [6-10]. From the pathophysiological point of view, dysregulated encephalitogenic $\mathrm{T}$ cells are thought to initiate and to orchestrate in concert with abundant other immune cells an autoimmune multifocal CNS inflammation [11-13]. For decades, MS was considered to be a primarily demyelinating disorder predominantly affecting the CNS white matter. During recent years, however, it has become clear that MS also has a strong neurodegenerative component, which is most probably the underlying basis for the development of permanent disability [14-17]. Moreover, grey matter involvement has been increasingly recognised by means of histopathology and magnetic resonance imaging (MRI) [18-20]. Paraclinical tools for diagnosis, differential diagnosis, and monitoring of disease activity and progression in MS comprise cerebrospinal fluid examination, evoked potentials, MRI, and recently, optical coherence tomography [1,21-24]. 
Current treatment concepts comprise the application of immunomodulatory or immunosuppressive drugs such as interferon-beta, glatiramer acetate, fingolimod, natalizumab, or mitoxantrone [25,26]. Approval of additional new drugs is expected. However, most if not all of these drugs lack convincing neuroprotective capacity. Moreover, a substantial number of patients do not respond satisfyingly to these drugs or experience severe side effects [27-31]. Overall, there is still a need for improved therapeutic approaches, especially in neuroprotective substances [32].

\section{Vitamin D: background information}

Research on VD started around 1915, stimulated by the quest for an effective treatment of rickets. By the end of the 19th century, up to $90 \%$ of the children living in large cities throughout Northern Europe and the United States suffered from rickets, and the most common cause was the insufficient supply of VD due to low sun exposure as a side effect of increasing industrialisation. The transformation to an industrialised economy radically changed the living conditions for large parts of the population. Children often had to work many hours a day in factories or mines, being completely shielded from the sun. When VD deficiency was recognised as the main cause of rickets, a significant reduction of cases was achieved by preventive measures like radiation from ultraviolet lamps, greater amount of time spent outdoors, or fortification of food with VD [33].

The VD supply of the human organism is generally accomplished via two different routes: first, endogenous synthesis of VD3 (cholecalciferol) from its precursor 7dehydrocholesterol in an ultraviolet (UV) B radiationdependent process in the skin (wave length 290 to $315 \mathrm{~nm}$ ); second, exogenous supply with VD3 or VD2 (ergocalciferol) by food, fortified food products, or supplements [34,35]. About $90 \%$ to $100 \%$ of the VD requirement of a human body is covered by sun exposure-dependent endogenous production $[33,36]$. The amount of UVB-radiation dependent VD production depends on numerous factors including individual factors like duration and frequency of sun exposure, the area of skin exposed to the sun, use of sun protection, skin pigmentation, age, sex, genetic factors, amounts of 7dehydrocholesterol in the skin; geographic factors like latitude and altitude; as well as seasonal and meteorological factors like clouding and ozone levels [36]. The magnitude of endogenous VD synthesis is referenced to the minimum erythema dose (MED) which describes the minimum individual dose of UVB radiation needed for the development of a transient skin irritation. One MED of the entire body equals the release of 10,000 to $20,000 \mathrm{IU}$ (250 to $500 \mu \mathrm{g}$ ) of VD3 [1]. Compared to the endogenous production of VD3, the food-related intake of VD2/3 is usually of inferior importance since only few food products contain significant amounts of VD (Table 1).
Table 1 Dietary sources of vitamin D [37]

\begin{tabular}{lll}
\hline Food product & $\begin{array}{l}\text { Vitamin D content } \\
(\boldsymbol{\mu g} / \mathbf{1 0 0 g})\end{array}$ & $\begin{array}{l}\text { Required daily intake } \\
\text { (in g) for } \mathbf{2 0} \boldsymbol{\mu} \mathbf{g} \text { vitamin } \mathbf{D}\end{array}$ \\
\hline Cod liver oil & 330 & 6 \\
Smoked eel & 22 & 91 \\
Salmon & 3.8 & 526 \\
Avocado & 3.43 & 583 \\
Egg yolk & 2.9 & 690 \\
Liver (beef) & 1.7 & 1,176 \\
Butter & 1.2 & 1,667 \\
Pork & 0.11 & 18,182 \\
Milk (3.5\%) & 0.088 & 22,727 \\
\hline
\end{tabular}

Both VD2 and VD3 are biologically inactive. After intradermal synthesis or intestinal uptake, VD2 and VD3 are bound mainly to vitamin-D-binding-protein and transported to the liver, where they are enzymatically hydroxylated to $25(\mathrm{OH}) \mathrm{VD}$ (calcidiol). As this step is not tightly regulated and because of the relatively long half-life, serum levels of 25(OH)VD integrate both the endogenous and exogenous supply and provide a good estimate of an organism's VD status. The enzyme $1 \alpha$-hydroxylase (CYP27B1), which is located mainly in the kidneys but also in other tissues, converts $25(\mathrm{OH}) \mathrm{VD}$ in a second hydroxylation step into the biologically active 1,25 dihydroxyvitamin D $\left(1,25(\mathrm{OH})_{2} \mathrm{VD}\right.$; calcitriol) [35]. Unlike the first hydroxylation, this second step is tightly regulated, among others by parathormone and calcium/phosphate levels [38]. Calcitriol effects are mainly mediated via the intracellular VD receptor (VDR) which functions as a transcription factor and controls the expression of numerous genes. In its membrane-bound form, VDR mediates additional nongenomic functions including several signal transduction pathways $[39,40]$.

An ongoing debate addresses the optimal serum levels of 25(OH)VD. Currently, most experts consider $25(\mathrm{OH})$ VD levels above $30 \mathrm{ng} / \mathrm{ml}(75 \mathrm{nmol} / \mathrm{l})$ as adequate [4143], which is supported by the observations that serum levels of parathormone start plateauing at serum $25(\mathrm{OH})$ $\mathrm{VD}$ of 30 to $40 \mathrm{ng} / \mathrm{ml}$ and that immunological effects need serum levels around $30 \mathrm{ng} / \mathrm{ml}[35,44]$. Levels below $20 \mathrm{ng} / \mathrm{ml}$ (50 nmol/l) are considered deficient. Less clear are the upper limits since substantial variability occurs in naturally occurring $25(\mathrm{OH}) \mathrm{VD}$ levels. According to the literature, levels of up to 150 to $200 \mathrm{ng} / \mathrm{ml}$ (375 to 500 $\mathrm{nmol} / \mathrm{l}$ ) can be considered safe [41]. Against this background, a significant proportion of the human population worldwide shows an alarming VD inadequacy [35,44-46].

Since VD homeostasis is linked on multiple levels to the risk of not only various diseases such as cancer and autoimmune diseases, but also metabolic, cardiovascular, and psychiatric disorders $[35,42,47,48]$, the question 
arises whether improvement of VD supply may prevent or even treat respective diseases. Indeed, recent estimations indicate that yearly, $>110,000$ deaths could be prevented by adequate VD supply [49].

\section{Linking vitamin $D$ and MS: immunoregulatory functions of vitamin D}

Apart from its fundamental role in calcium homeostasis and bone metabolism, increasing evidence suggests that VD has additional, particularly immunoregulatory functions which renders VD a promising candidate in both pathogenesis and treatment of autoimmune diseases such as MS. The capability of VD to modulate both innate and adaptive immune responses has been summarised in several comprehensive and excellent reviews [47,50-52]. With respect to the autoimmune MS pathophysiology $[11,12]$, the following effects of VD on the immune system might be of particular interest: the ability to modulate the differentiation and function of antigen presenting cells which results in a reduced activation of potentially autoaggressive T cells [53-55], the capacity to inhibit B cell and $\mathrm{T}$ cell proliferation and differentiation [56-58], the ability to shift the cytokine milieu from a pro-inflammatory, Th1/ Th17-cell-mediated to a rather anti-inflammatory Th2cell-mediated state $[47,59]$, and finally, to facilitate the differentiation of regulatory $T$ cells and function of natural killer cells $[60,61]$. Data on the VD effect on CD8 cells are still controversial. Figure 1 summarises the potential immunoregulatory effects of VD that might be pathophysiologically relevant in MS.

The presence of $1 \alpha$-hydroxylase activity in neurons and microglia, and the presence of VD receptor in the CNS suggest local-, paracrine-, or autocrine-mediated effects of VD in the CNS [63,64]. Interestingly, data from in vitro or animal studies suggest that neurotrophic factors such as nerve growth factor, neurotrophin 3 , and glial cell linederived neurotrophic factor are regulated by VD which might indicate additional, possibly neuroprotective effects of VD [65]. Whether VD has clinically relevant neuroprotective properties still remains a subject of discussion.

\section{Linking vitamin D and MS: how do genes contribute?}

It is long known that genetic factors contribute to the risk of MS. In particular, an association with extended major histocompatibility complex haplotypes, especially those containing HLA-DRB1*1501, has been consistently shown in individuals of northern European ancestry $[66,67]$. The role of VD-related genes in determining MS risk or specific genetic interactions with VD is currently a hot focus of research and is not yet completely understood. So far, two interesting links merit mentioning: First, it was recently shown that the gene expression of allele HLA-DRB1*1501 is modulated by VD, and a highly conserved VD-responsive element has been identified in the promoter region of the HLA-DRB1*1501 haplotype, which may indicate a direct functional interaction between VD

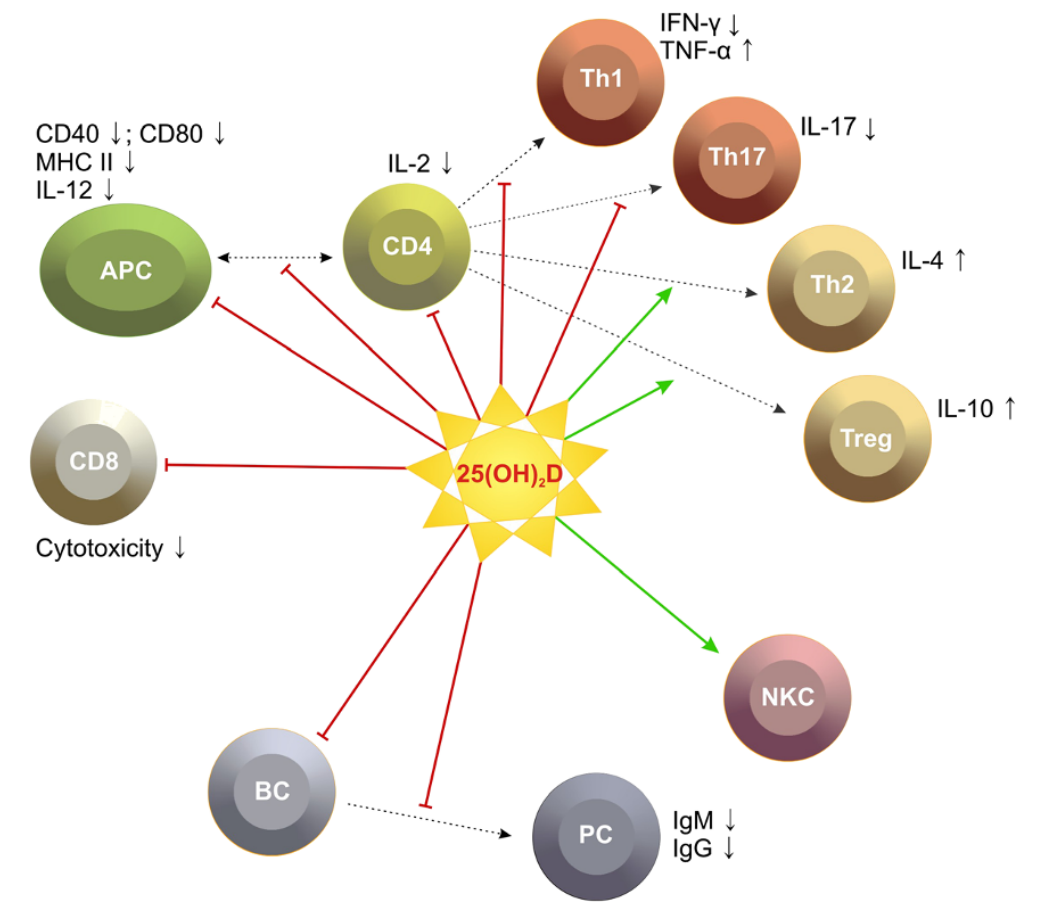

Figure 1 Possible effects of vitamin D on immune cells. APC, antigen presenting cell; Th, T helper cell; Treg, regulatory T cell; BC, B cell; PC, plasma cell; NKC, natural killer cell. Figure was first published in [62]. 
and the major locus determining genetic susceptibility to MS [68]. Second, loss of function variants in the CYP27B1 gene which encodes the enzyme that converts $25(\mathrm{OH}) \mathrm{VD}$ into its active form were shown to be associated with an increased MS risk [69]. In the same direction points a possible association between MS and VD-dependent rickets type $\mathrm{I}$, which is a rare hereditary condition caused by a mutation in CYP27B1 [70,71].

\section{Linking vitamin D and MS: what do animal models tell us?} Further evidence for a causal relation between VD supply and both development and treatment of MS were derived from experimental autoimmune encephalomyelitis (EAE), the best established rodent animal model for MS. In murine EAE, prophylactic application of VD (starting at disease induction) resulted in a reduction of both disease incidence and severity. Likewise, the therapeutic VD application (starting at onset of symptoms) lead to a significant reduction of disease severity [72-74]. Interestingly, some studies suggested gender-specific efficacy of VD only in female mice [75]. In a recent study, continuous treatment of mice with UVR dramatically suppressed clinical signs of EAE. Interestingly, the therapeutic effect was paralleled by only a moderate and transient increase of serum 25(OH)VD levels, which suggests that directly UVR-mediated effects which were at least partly independent of VD contributed to this observation [76]. In another recent study using the cuprizone model, dietary VD could (partly) prevent chemically induced CNS demyelination in mice [77].

\section{Linking vitamin D and MS: the clue to geographic and seasonal associations?}

First hypotheses on a possible link between MS risk and VD deficiency were derived from the observation that the risk of MS is associated with latitude [78,79] which in turn shows a strong inverse correlation with UVB exposure. Furthermore, migrating from high to low latitude appears to reduce the MS risk [80]. This link was further corroborated by the observation of a MS risk lower than one would expect from the latitude in regions with a high consume of fatty VD-rich fish [81]. More recent investigations, however, suggest that this latitude gradient is fading which might be explained by several possible reasons, including better MS recognition, changes in lifestyle, and improvement of sanitary circumstances [34]. More indirect though not unambiguous support for a beneficial effect of VD comes from the observation that both MS risk and disease activity show a seasonal association. As shown in several studies including a very recent meta-analysis, humans born in spring have a significant higher risk to develop MS later in life than people born in autumn [82-85] which might be at least partially explained by longer in utero VD insufficiency due to lower motherly VD levels in winter/spring as compared to summer/autumn. Likewise, several methodically high quality studies showed an inverse association between sun exposure or outdoor activities during childhood and adolescence, and the risk of developing MS during adulthood [86-90]. In line with these reports is the recent observation that low sun exposure in fall/winter before disease onset was associated with a less favourable outcome [91]. Yet, all these studies have two major intrinsic limitations: first, despite a reported reasonable validity and reliability [92], the retrospective determination of sun exposure years or even decades in the past is inevitably subjected to recall bias [34], and prospective studies are hardly available. The determination of actinic damage as a surrogate parameter for cumulative sun exposition might be a viable loophole $[34,86]$. Second, sun exposure itself may have intrinsic immunomodulatory effects, independent of VD $[76,93,94]$. Also, not easy to harmonise with sun exposure or VD synthesis is the seasonal dependency of disease activity in already established MS. Several studies including a meta-analysis showed an excess of clinical exacerbations and MRI activity in spring/ summer and a nadir in autumn/winter in the northern hemisphere [95-98]. Correspondingly, a reverse situation was observed in the southern hemisphere [99]. While a peak of disease activity in spring and a nadir in autumn in the northern hemisphere could be explained with a fewmonth lag in the course of serum VD levels, the situation in summer and winter does not easily fit with a protective role of VD. In conclusion, VD might contribute to some but cannot sufficiently explain all geographic and seasonal associations observed in MS.

\section{Linking vitamin $D$ and MS: the impact of vitamin $D$ intake and serum level}

The rather indirect impact of predictors of 25(OH)VD levels on MS has been discussed above. But, how does the 25(OH)VD serum level itself sway the risk and course of MS? Generally, if VD had a beneficial effect on MS risk, one would demand an inverse relation between VD intake or serum levels and MS incidence. Indeed, various studies demonstrated such a relation. Most data on this issue, however, are derived from epidemiologic or observational studies, meaning, that methodical limitations like selection bias, retrospective survey, and interference with various confounders should be kept in mind. One recent study suggests that already in utero levels of $\mathrm{VD}$, which are completely dependent on the mother's VD status, impact the risk to develop MS later in life [100]. In a Canadian cohort study on children presenting with a first demyelinating event, the risk to develop definite MS within the following 3 years was inversely and independently correlated with the $25(\mathrm{OH})$ VD serum level [101]. Furthermore, data from a nested case-control study involving more than seven million individuals of the US military suggest that in 
healthy young white adults, higher 25(OH)VD levels are predictive of a significantly lower risk of developing MS (62\% lower odds in the top quintile of $25(\mathrm{OH}) \mathrm{VD}$ serum levels compared to the bottom quintile), independent from latitude of residency in childhood [102]. Another study by the same group addressed the relation between VD intake and MS risk in a cohort of approximately 200,000 US women and reported a 33\% reduction of MS incidence over a follow-up period of 30 years when comparing the top quintile and the bottom quintile of VD intake. Moreover, in women taking daily supplements containing at least $400 \mathrm{IU}$ VD, a $41 \%$ lower MS incidence was observed when compared to women who did not take supplements [103]. Likewise, in another survey, intake of cod liver oil was associated with a 4-year delay of MS onset [90]. In summary, substantial evidence exists for an inverse association between VD and the risk of developing MS.

But, how does the situation look in already established MS? A number of studies consistently suggest that higher VD serum levels are associated with a more favourable disease course. In a small Finnish study, lower summer 25 $(\mathrm{OH}) \mathrm{VD}$ concentrations were measured in patients with a first MS relapse compared to healthy controls, and 25 $(\mathrm{OH}) \mathrm{VD}$ concentrations were significantly lower during relapses than in remission phases which may point to a regulative role of VD for MS activity [104]. Compelling support for this hypothesis comes from four independent recent reports, all showing a close relationship between clinical disease activity and 25(OH)VD concentrations: Two studies demonstrated that every $10 \mathrm{nmol} / \mathrm{l}$ increase of the VD serum level is correlated with a reduction of relapse occurrence of $11 \%$ and $13.7 \%$, respectively $[105,106]$. A third study demonstrated a log linear association between serum VD concentration and MS relapse rate in that every doubling of serum levels reduced relapse rate by $27 \%$ [107]. The fourth study finally revealed a $34 \%$ reduction of relapse rate by every $10 \mathrm{ng} / \mathrm{ml}$ increase in paediatric onset MS [108]. In line with these clinical data, an inverse association between VD concentrations and disease activity on cranial MRI was recently demonstrated, but may possibly be restricted to patients without additional immunomodulatory treatment $[109,110]$. Of note, in studies addressing the relation between clinical disease activity and VD levels, a reverse association (low VD concentrations as a consequence rather than a cause of a relapse) cannot be completely ruled out. In contrast to the serum concentrations, a statistical difference in cerebrospinal fluid VD levels was neither observed between MS patients and healthy controls or in MS patients between phases of disease activity or in remission [111].

In conclusion, cumulating evidence quite consistently argues for a relationship between VD status and both risk and activity of MS. Of note, however, all these studies are methodically prone to bias and are therefore not suited to definitely proof such a relation.

\section{Linking vitamin D and MS: what do interventional trials tell us?}

The compelling evidence for the beneficial impact of higher VD serum concentrations on disease activity leads directly to two questions: (a) do patients with already established MS benefit from a therapeutic elevation of their VD levels and (b) if so, which 25(OH)VD serum levels should be strived for in MS patients? To reliably answer these crucial questions, high quality and sufficiently powered interventional trials are required. Moreover, important issues like optimal dosing schemes need further clarification. So far, there are only few prospective clinical studies on VD as a treatment for MS, some of them of rather questionable quality. An early uncontrolled study involving $16 \mathrm{MS}$ patients (evidence level IIb) showed that regular intake of cod liver oil (equivalent to 5,000 IU VD/ day) for a period of up to 2 years lead to a lower relapse rate as would have been expected from the participants' medical histories [112]. From today's point of view, design and sample size of this study are however not appropriate to address a therapeutic effect of VD. Another small and uncontrolled study with a primary focus on safety aspects (evidence level IIb) provided evidence that escalating VD doses up to 280,000 IU/week over a rather short period of 28 weeks are safe in MS patients. No significant effects on clinical parameters were observed, but there was a possible effect on MRI activity [113]. In a successive randomised controlled but open label study, the same group applied cholecalciferol (up to 40,000 or 4,000 IU/d) continuously for 52 weeks in 49 MS patients (evidence level Ib). Patients in the high dose arm showed a significant reduction of the annualised relapse rate [114]. In another randomised double blind and placebo-controlled study focusing on serological markers of disease activity (evidence level IIb), administration of 1,000 IE cholecalciferol for a period of 6 months lead to a significant increase of the anti-inflammatory cytokine transforming growth factor- $\beta$ and to a partial reduction of the IL-2 level [115]. Another recent study (evidence level IIb) reported no significant differences between the high- or low-dose ergocalciferol on clinical and MRI parameters [116]. However, the design of this study (small number, inhomogeneous group of patients, short period of observation, relatively high dosages of "low-dose" ergocalciferol) has been criticised as not being suited to address the therapeutic capacity of VD in MS [117]. The capacity of low dose calcitriol to prevent disease progression in relapsing remitting multiple sclerosis (RRMS) when given in adjunction to undefined disease-modifying treatment strategies was investigated in a randomised and double blind but rather small study on 50 patients. After 12 months, no significant 
Table 2 Ongoing clinical trials on vitamin D in multiple sclerosis (registered at www.clinicaltrials.gov by January 2013)

\section{Trial title/registration number}

Phase II study of efficacy of

vitamin D supplementation in

multiple sclerosis (EVIDIMS study)

Universitätsmedizin

Berlin, Germany

NCT01440062

Supplementation of VigantOL ${ }^{\circledR}$

oil versus placebo as add-on in

patients with relapsing remitting

multiple sclerosis receiving

Rebif ${ }^{\mathbb{Q}}$ treatment (SOLAR study)

NCT01285401
Start date/estimated Intervention

ion date

December 2011/

Cholecalciferol 20,400 IU

every other day (high

dose) or cholecalcifero

$400 \mathrm{IU} /$ every other day

Add-on to IFN $\beta 1$ b 250

$\mu \mathrm{g}$ every other day
March 2015

(low dose) for 18 months
Trial design

Randomised double

blind active controlled multicenter Phase II

80 patients with

RRMS or CIS

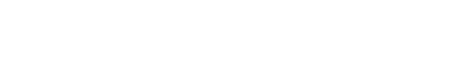

\section{Number of}

Main outcome parameters

Primary: cumulative number of new T2 lesions

Secondary: annualised relapse rate occurrence of disability progression proportion of patients without disease activity, conversion rate into definite MS, cumulative number of 11 gadolinium Tl gadolinium enhancing lesion, hypointense lesions, number and hypointense lesions, number and esions, changes in brain parenchymal volume, changes in magnet resonance spectroscopy, changes in retinal structure as determined by optical coherence tomography, changes in cognitive tomography, changes in cognitive health-related quality of life

\section{Merck-Serono GmbH} Cholecalciferol 14,000 IU/

Add-on to IFN $\beta 1$ a $44 \mu \mathrm{g}$ 3x/week

Cholecalciferol $2 x$ $100,000 \mathrm{IU} / \mathrm{month}$ or placebo for 96 week
Randomised double blind placebocontrolled multicenter phase II trial RRMS

48 patients with

Primary: mean number of active lesions at week, proportion of relapse-free subjects

Secondary: annualised relapse rate proportion of subjects free from any EDSS progression, proportion of subjects free from disease activity, change in cognitive function, cumulative number of $\mathrm{T} 1$ gadolinium enhancing lesion, proportion of subjects free from new $T$

hypointense lesions, change from hypointense lesions, change from baseline in the total volume of lesions, percent brain volume change with respect to baseline

Randomised double blind placebo-

250 patients with Primary: reduction of relapse rate RRMS controlled multicenter 
Table 2 Ongoing clinical trials on vitamin D in multiple sclerosis (registered at www.clinicaltrials.gov by January 2013) (Continued)

NCT01198132 Add-on to IFN $\beta 1$ 1a $44 \mu 9$

Secondary: number of relapse-free subjects, cumulative probability of progression of disability, number of new or extended lesions in T1- and T2-weighted MRI, changes in - and I2-weighted MRl, changes in lesion load (T2), number of new lesions (T1 gadolinium activity and black holes), measurement and evaluation of cognitive ability, change in quality of life, safety of the treatment effects of low dose versus high
A pilot study to assess the relative safety and immunology dose cholecalciferol

supplementation in patients with multiple sclerosis

\section{Primary: safety of high-dose}

cholecalciferol, effects of

cholecalciferol supplementation

on serum immune markers

NCT01024777

A randomised controlled trial of vitamin D supplementation in multiple sclerosis

\section{Johns Hopkins University, March 2010/} Baltimore, USA December 2011

Johns Hopkins University, Baltimore, USA

NCT01490502
Cholecalciferol 10,000 IU/ Randomised double cholecalciferol $400 \mathrm{IU} /$ day multicenter phase II (low dose) for 6 months day (high dose) or blind controlled
40 MS patients with or without immunomodulatory treatment and serum 25(OH)VD levels between 20 $50 \mathrm{ng} / \mathrm{ml}$
Randomised double day (high dose) or cholecalciferol $600 \mathrm{IU} / \mathrm{day}$

Add-on to glatiramer acetate $20 \mathrm{mg} / \mathrm{day}$
Pharmacodynamic and

immunologic effects of vitamin $D$ supplementation in patients with

multiple sclerosis and healthy

controls

NCT01667796
Johns Hopkins University, November 2010/June Baltimore, USA 2013 day for 90 days
Non-randomised open label single group assignment trial
Secondary: clinical effects of cholecalciferol supplementation

72 RRMS patients Primary: proportion of subjects that with 25(OH)Dserum levels $\geq 15$ $\mathrm{ng} / \mathrm{ml}$

Secondary: annualised relapse rate occurrence of sustained disability progression, number of new T2 lesions, changes in brain parenchymal volume and cortical thickness, change in low-contrast visual acuity, change in healthrelated quality of life, development of hypercalcemia/related adverse effects

60 patients with Primary: change in mean serum level RRMS or healthy of 25(OH)VD

individuals

Secondary: cytokine levels and percentages of $T$ and $B$ cells, gene expression microarray 
Table 2 Ongoing clinical trials on vitamin D in multiple sclerosis (registered at www.clinicaltrials.gov by January 2013) (Continued)

Role of vitamin D on the relapse

rate of multiple sclerosis

AlJohara M AlQuaiz, M.D.

King Saud University,

Janury

University College Dublin, November 2012/May Ireland

2014

Dose-related effects of vitamin

patients with clinicaly

syndrome and healthy control

participants. An exploratory

double blind placebo

randomised controlled study

Primary: change in the frequency

of CD4 T cell subsets and

cytokine responses of periphery

blood mononuclear cells

NCT01728922

holecalciferol 5,000 IU/

day or $10,000 \mathrm{IU} /$ day or

controlled phase II

tria
Randomised double

blind placebo-

200 patients with Primary: relapse rate

blind

single centre phase

trial

Secondary: improvement in the EDSS score

immunomodulatory treatment and

39 healthy individuals

Secondary: relapse occurrence

percentage of CIS patients in each

treatment arm free from any

evidence of disease activity, number

of new T2 and gadolinium-

enhancing lesions 
differences between verum and placebo arms were observed with respect to relapse rate and disability [118]. Two recently published studies from Finland and Norway, both applying 20,000 IU/week in a randomised, double blind and placebo-controlled design (evidence level Ib), yielded partly contradictory results with respect to clinical and MRI parameters. In the Finish study, mean 25(OH) VD serum levels in patients receiving VD over 1 year in addition to IFN- $\beta$ increased to $110 \mathrm{nmol} / \mathrm{l}$, and patients in the verum group showed significantly fewer gadoliniumenhancing lesions and a tendency to reduced disability accumulation and improved ambulation parameters. The annualised relapse rate was not different in both arms [119]. In an active subgroup of this study, an additional beneficial effect of VD on new/enlarging T2 hyperintense brain lesions was observed [120]. In the 96-week Norwegian trial, no significant differences were observed in annualised relapse rate, EDSS, MSFC, grip strength, or fatigue although the median $25(\mathrm{OH}) \mathrm{VD}$ serum concentration in the verum group raised to $121 \mathrm{nmol} / \mathrm{l}$ [121].

In summary, due to their ambiguous results, the so-far published interventional trials do not answer the question whether VD would be a treatment option in MS. The reasons for these heterogeneous results remain unclear. Given the substantial increase in serum concentration to greater $100 \mathrm{nmol} / \mathrm{l}$ in the two most recent trials [119,121], insufficient dosing is probably not a likely explanation. Further, well-designed interventional high-dose trials, which are at least partly better powered, are currently underway (Table 2) [122,123] and will hopefully contribute to elucidate the efficacy aspects.

With respect to safety, more clinical data already exist. Generally, (iatrogenic) VD excess can result in lifethreatening hypercalcaemia and has been occasionally reported on the basis of single cases [124]. However, unlike supplementation with high dose calcitriol, which indeed seems to bear a significant risk of symptomatic hypercalcaemia [125], treatment of MS patients with even very high doses of cholecalciferol or ergocalciferol was repeatedly demonstrated to be safe $[113,114,116,119,121]$. While a Cochrane report published in 2010 concludes that available data are not yet sufficient to draw the right conclusions regarding safety of VD supplementation [126], another recent meta-analysis suggests that daily doses of 10,000 IE cholecalciferol can be considered safe [127].

\section{Conclusions}

In this review article, which follows the recommendations of the "EPMA White Paper" [128], we summarise and discuss available data on the role of VD for the development and disease course of MS. Many lines of evidence, in particular epidemiologic data, preclinical investigations, animal studies, and association studies on VD status and disease activity, suggest that higher serum concentrations of VD are beneficial in terms of the risk to develop MS as well as the further course of the disease in already-established MS. Moreover, VD supplementation is safe, cheap, and convenient to perform. Therefore, it is intriguing to hypothesise that boosting the VD serum levels would be an option to both prevent and treat MS. Despite the inherent methodological drawbacks of epidemiologic studies, existing data on the preventive capacity of higher VD levels are quite compelling. Final proof of this hypothesis would be reached by large-scale prospective epidemiological studies which will probably not be available in the near future, for obvious reasons. With respect to the therapeutic efficacy, an association between higher VD serum concentrations and a favourable disease course has been conclusively shown. Unfortunately, the so-far performed interventional trials, though not negotiating this hypothesis, also do not unambiguously support the idea that raising patients' VD levels would be favourably in terms of disease outcome. Hopefully, ongoing (Table 2) and future trials will shed more light on this aspect.

But, how are we going to deal with this issue in the meantime? From a pragmatical point of view and considering available data on efficacy, safety, tolerability, and last but not least costs, it seems to be reasonable to regularly control 25(OH)VD levels in MS patients, especially during winter months. In patients with inadequate VD, levels should be raised to at least $30-40 \mathrm{ng} / \mathrm{ml}(75-100 \mathrm{mmol} / \mathrm{l})$, either by appropriate sun exposure and/or adequate VD supplementation. As a rule of thumb, supplementary $1 \mu \mathrm{g}$ (40 IU) cholecalciferol will increase 25(OH)VD levels by 1 $\mathrm{ng} / \mathrm{ml}(2.5 \mathrm{nmol} / \mathrm{l})$.

\section{Competing interests}

JD received a limited grant for clinical research on vitamin D by Bayer Healthcare, speaker honoraria by Bayer Healthcare, Novartis, and Teva, consultancy honoraria by Bayer Healthcare, and travel support by MerckSerono, Novartis, and Bayer Healthcare. FP received speaker honoraria and travel support by Bayer Healthcare, Teva, Sanofi-Aventis/Genzyme, Biogen Idec, Novartis, and Merck-Serono. FP is supported by the Artur-Arnstein Foundation Berlin, Germany, and has received travel reimbursement from the Guthy Jackson Charitable Foundation. AD declares no competing interests.

\section{Authors' contributions}

$A D$ and JD drafted the manuscript and did the literature search. FP critically revised the manuscript for important intellectual content. All authors read and approved the final manuscript.

\section{Authors' information}

JD is a neurologist and a senior physician/scientist at the NeuroCure Clinical Research Center (NCRC), Charité-Universitätsmedizin Berlin, Germany, and has a research focus on the role of VD in MS. As head of the NCRC

Neuroimmunological Study Outpatient Department, he is currently running a therapeutic phase II clinical trial on VD in MS. AD is a physician; she completed part of her neurological training at the NCRC. FP is a senior neurologist and head of the Neuroimmunological Group at the NCRC. His research focus is the translation of new diagnostic tools and therapeutic approaches in MS and related disorders into the clinical setting.

Acknowledgments

This work was supported by the DFG (Exc 257). 


\section{Author details}

${ }^{1}$ NeuroCure Clinical Research Center, Charité - Universitätsmedizin Berlin, Charitéplatz 1, Berlin 10117, Germany. ${ }^{2}$ Clinical and Experimental Research Center for Multiple Sclerosis, Charité - Universitätsmedizin Berlin, Berlin, Germany. ${ }^{3}$ Current address: Department of Neurology, DIAKO, Flensburg, Germany.

Received: 30 November 2012 Accepted: 9 January 2013

Published: 29 January 2013

\section{References}

1. Compston A, Coles A: Multiple sclerosis. Lancet 2008, 372:1502-1517.

2. Weinges-Evers N, Brandt AU, Bock M, Pfueller CF, Dörr J, Bellmann-Strobl J, Scherer P, Urbanek C, Boers C, Ohlraun S, Zipp F, Paul F: Correlation of self-assessed fatigue and alertness in multiple sclerosis. Mult Scler 2010, 16:1134-1140

3. Veauthier C, Radbruch H, Gaede G, Pfueller C, Dörr J, Bellmann-Strobl J, Wernecke K-D, Zipp F, Paul F, Sieb J: Fatigue in multiple sclerosis is closely related to sleep disorders: a polysomnographic cross-sectional study. Mult Scler 2011, 17:613-622.

4. Handel AE, Jarvis L, McLaughlin R, Fries A, Ebers GC, Ramagopalan SV: The epidemiology of multiple sclerosis in Scotland: inferences from hospital admissions. PLoS One 2011, 6:e14606.

5. Borisow N, Döring A, Pfueller CF, Paul F, Dörr J, Hellwig K: Expert recommendations to personalization of medical approaches in treatment of multiple sclerosis: an overview of family planning and pregnancy. EPMA J 2012, 3:9.

6. Ascherio A, Munger $\mathrm{KL}$ : Environmental risk factors for multiple sclerosis. Part I: the role of infection. Ann Neurol 2007, 61:288-299.

7. Ascherio A, Munger KL: Environmental risk factors for multiple sclerosis. Part II: noninfectious factors. Ann Neurol 2007, 61:504-513.

8. Handel AE, Giovannoni G, Ebers GC, Ramagopalan SV: Environmental factors and their timing in adult-onset multiple sclerosis. Nat Rev Neurol 2010, 6:156-166.

9. Goodin DS: The causal cascade to multiple sclerosis: a model for MS pathogenesis. PLoS One 2009, 4:e4565.

10. Ramagopalan SV, Dobson R, Meier UC, Giovannoni G: Multiple sclerosis: risk factors, prodromes, and potential causal pathways. Lancet Neurol 2010, 9:727-739

11. McFarland HF, Martin R: Multiple sclerosis: a complicated picture of autoimmunity. Nat Immunol 2007, 8:913-919.

12. Nylander A, Hafler DA: Multiple sclerosis. J Clin Invest 2012, 122:1180-1188.

13. Haegert DG: Multiple sclerosis: a disorder of altered T-cell homeostasis. Mult Scler Int 2011, 2011:461304.

14. Trapp BD, Peterson J, Ransohoff RM, Rudick RA, Mork S, Bo L: Axonal transection in the lesions of multiple sclerosis. N Engl J Med 1998, 338:278-285.

15. Peterson JW, Bo L, Mork S, Chang A, Trapp BD: Transected neurites, apoptotic neurons, and reduced inflammation in cortical multiple sclerosis lesions. Ann Neurol 2001, 50:389-400.

16. De Stefano N, Matthews PM, Fu L, Narayanan S, Stanley J, Francis GS, Ante $J P$, Arnold DL: Axonal damage correlates with disability in patients with relapsing-remitting multiple sclerosis. Results of a longitudinal magnetic resonance spectroscopy study. Brain 1998, 121(Pt 8):1469-1477.

17. Vogt J, Paul F, Aktas O, Muller-Wielsch K, Dörr J, Dörr S, Bharathi BS, Glumm R, Schmitz C, Steinbusch H, Raine CS, Tsokos M, Nitsch R, Zipp F: Lower motor neuron loss in multiple sclerosis and experimental autoimmune encephalomyelitis. Ann Neurol 2009, 66:310-322

18. Kutzelnigg A, Lucchinetti CF, Stadelmann C, Brück W, Rauschka H, Bergmann M, Schmidbauer M, Parisi JE, Lassmann H: Cortical demyelination and diffuse white matter injury in multiple sclerosis. Brain 2005, 128:2705-2712.

19. Sinnecker T, Mittelstaedt P, Dörr J, Pfueller CF, Harms L, Niendorf T, Paul F, Wuerfel J: Multiple sclerosis lesions and irreversible brain tissue damage: a comparative ultrahigh-field strength magnetic resonance imaging study. Arch Neurol 2012, 69:739-745.

20. Sinnecker T, Dörr J, Pfueller CF, Harms L, Ruprecht K, Jarius S, Brück W, Niendorf T, Wuerfel J, Friedemann P: Distinct lesion morphology at 7-T MRI differentiates neuromyelitis optica from multiple sclerosis. Neurology 2012, 79:708-714
21. Bock M, Brandt AU, Dörr J, Kraft H, Weinges-Evers $N$, Gaede G, Pfueller CF, Herges K, Radbruch H, Ohlraun S, Bellmann-Strobl J, Kuchenbecker J, Zipp F, Paul F: Patterns of retinal nerve fiber layer loss in multiple sclerosis patients with or without optic neuritis and glaucoma patients. Clin Neurol Neurosurg 2010, 112:647-652

22. Oberwahrenbrock T, Schippling S, Ringelstein M, Kaufhold F, Zimmermann H, Keser N, Young KL, Harmel J, Hartung H-P, Martin R, Paul F, Aktas O, Brandt AU: Retinal damage in multiple sclerosis disease subtypes measured by high-resolution optical coherence tomography. Mult Scler Int 2012, 2012:530305.

23. Dörr J, Wernecke KD, Bock M, Gaede G, Wuerfel JT, Pfueller CF, BellmannStrobl J, Freing A, Brandt AU, Friedemann P: Association of retinal and macular damage with brain atrophy in multiple sclerosis. PLoS One 2011, 6:e18132.

24. Polman CH, Reingold SC, Banwell B, Clanet M, Cohen JA, Filippi M, Fujihara K, Havrdova E, Hutchinson M, Kappos L, Lublin FD, Montalban X, O'Connor $P$, Sandberg-Wollheim M, Thompson AJ, Waubant E, Weinshenker B, Wolinsky JS: Diagnostic criteria for multiple sclerosis: 2010 revisions to the McDonald criteria. Ann Neurol 2011, 69:292-302.

25. Río J, Comabella M, Montalban X: Multiple sclerosis: current treatment algorithms. Curr Opin Neurol 2011, 24:230-237.

26. Buck D, Hemmer B: Treatment of multiple sclerosis: current concepts and future perspectives. J Neurol 2011, 258:1747-1762.

27. Jain N, Bhatti MT: Fingolimod-associated macular edema: incidence, detection, and management. Neurology 2012, 78:672-680.

28. Paul F, Dörr J, Wurfel J, Vogel HP, Zipp F: Early mitoxantrone-induced cardiotoxicity in secondary progressive multiple sclerosis. $J$ Neurol Neurosurg Psychiatry 2007, 78:198-200

29. Sorensen PS, Bertolotto A, Edan G, Giovannoni G, Gold R, Havrdova E, Kappos L, Kieseier BC, Montalban X, Olsson T: Risk stratification for progressive multifocal leukoencephalopathy in patients treated with natalizumab. Mult Scler 2012, 18:143-152.

30. Giovannoni G, Southam E, Waubant E: Systematic review of diseasemodifying therapies to assess unmet needs in multiple sclerosis: tolerability and adherence. Mult Scler 2012, 18:932-946.

31. Limmroth $\mathrm{V}$, Putzki $N$, Kachuck NJ: The interferon beta therapies for treatment of relapsing-remitting multiple sclerosis: are they equally efficacious? A comparative review of open-label studies evaluating the efficacy, safety, or dosing of different interferon beta formulations alone or in combination. Ther Adv Neurol Disord 2011, 4:281-296.

32. Fox RJ: Primary neuroprotection: the Holy Grail of multiple sclerosis therapy. Neurology 2010, 74:1018-1019.

33. Holick MF: Vitamin D: a millenium perspective. J Cell Biochem 2003 88:296-307.

34. Ascherio A, Munger KL, Simon KC: Vitamin D and multiple sclerosis. Lancet Neurol 2010, 9:599-612.

35. Holick MF: Vitamin D deficiency. N Engl J Med 2007, 357:266-281.

36. Hagenau T, Vest R, Gissel TN, Poulsen CS, Erlandsen M, Mosekilde L, Vestergaard P: Global vitamin D levels in relation to age, gender, skin pigmentation and latitude: an ecologic meta-regression analysis. Osteoporos Int 2009, 20:133-140.

37. Database of the German Institut für Ernährungsinformation, Freudenstadt, Germany; [http://www.ernaehrung.de/lebensmittel]

38. White $\mathrm{JH}$ : Regulation of intracrine production of 1,25-dihydroxyvitamin D and its role in innate immune defense against infection. Arch Biochem Biophys 2012, 523:58-63.

39. Haussler MR, Jurutka PW, Mizwicki M, Norman AW: Vitamin D receptor (VDR)-mediated actions of $1 a, 25(\mathrm{OH})_{2}$ vitamin $\mathrm{D}_{3}$ : genomic and nongenomic mechanisms. Best Pract Res Clin Endocrinol Metab 2011, 25:543-559.

40. Carlberg C, Molnar F: Current status of vitamin D signaling and its therapeutic applications. Curr Top Med Chem 2012, 12:528-547.

41. Holick MF: Vitamin D status: measurement, interpretation, and clinical application. Ann Epidemiol 2009, 19:73-78

42. Souberbielle JC, Body JJ, Lappe JM, Plebani M, Shoenfeld Y, Wang TJ, Bischoff-Ferrari HA, Cavalier E, Ebeling PR, Fardellone P, Gandini S, Gruson D, Guérin AP, Heickendorff L, Hollis BW, Ish-Shalom S, Jean G, Von Landenberg P, Largura A, Olsson T, Pierrot-Deseilligny C, Pilz S, Tincani A, Valcour A, Zittermann A: Vitamin D and musculoskeletal health, cardiovascular disease, autoimmunity and cancer: Recommendations for clinical practice. Autoimmun Rev 2010, 9:709-715. 
43. Bischoff-Ferrari HA: Optimal serum 25-hydroxyvitamin D levels for multiple health outcomes. Adv Exp Med Biol 2008, 624:55-71.

44. Thomas MK, Lloyd-Jones DM, Thadhani RI, Shaw AC, Deraska DJ, Kitch BT, Vamvakas EC, Dick IM, Prince RL, Finkelstein JS: Hypovitaminosis D in medical inpatients. N Engl J Med 1998, 338:777-783.

45. Holick MF: High prevalence of vitamin D inadequacy and implications for health. Mayo Clin Proc 2006, 81:353-373.

46. Hintzpeter B, Mensink GBM, Thierfelder W, Müller MJ, Scheidt-Nave C: Vitamin D status and health correlates among German adults. Eur J Clin Nutr 2008, 62:1079-1089.

47. Peelen E, Knippenberg S, Muris AH, Thewissen M, Smolders J, Tervaert JWC, Hupperts R, Damoiseaux J: Effects of vitamin D on the peripheral adaptive immune system: a review. Autoimmun Rev 2011, 10:733-743.

48. Fleet JC, DeSmet M, Johnson R, Li Y: Vitamin D and cancer: a review of molecular mechanisms. Biochem J 2012,441:61-76.

49. Grant WB: An estimate of the global reduction in mortality rates through doubling vitamin D levels. Eur J Clin Nutr 2011, 65:1016-1026.

50. Deluca HF, Cantorna MT: Vitamin D: its role and uses in immunology. FASEB J 2001, 15:2579-2585.

51. Correale J, Ysrraelit MC, Gaitán MI: Immunomodulatory effects of Vitamin D in multiple sclerosis. Brain 2009, 132:1146-1160.

52. Di Rosa M, Malaguarnera M, Nicoletti F, Malaguarnera L: Vitamin D3: a helpful immuno-modulator. Immunology 2011, 134:123-139.

53. Almerighi C, Sinistro A, Cavazza A, Ciaprini C, Rocchi G, Bergamini A: 1Alpha,25-dihydroxyvitamin D3 inhibits CD40L-induced proinflammatory and immunomodulatory activity in human monocytes. Cytokine 2009, 45:190-197.

54. Piemonti L, Monti P, Sironi M, Fraticelli P, Leone BE, Dal Cin E, Allavena P, Di Carlo V: Vitamin D3 affects differentiation, maturation, and function of human monocyte-derived dendritic cells. J Immunol 2000, 164:4443-4451.

55. Griffin MD, Lutz W, Phan VA, Bachman LA, McKean DJ, Kumar R: Dendritic cell modulation by 1alpha, 25 dihydroxyvitamin D3 and its analogs: a vitamin $D$ receptor-dependent pathway that promotes a persistent state of immaturity in vitro and in vivo. Proc Natl Acad Sci USA 2001, 98:6800-6805

56. Lemire JM, Adams JS, Sakai R, Jordan SC: 1 alpha,25-dihydroxyvitamin D3 suppresses proliferation and immunoglobulin production by normal human peripheral blood mononuclear cells. J Clin Invest 1984, 74:657-661.

57. Chen S, Sims GP, Chen XX, Gu YY, Chen S, Lipsky PE: Modulatory effects of 1,25-dihydroxyvitamin D3 on human B cell differentiation. J Immunol 2007, 179:1634-1647.

58. Bhalla AK, Amento EP, Serog B, Glimcher LH: 1,25-dihydroxyvitamin D3 inhibits antigen-induced T cell activation. J Immunol 1984, 133:1748-1754

59. Boonstra A, Barrat FJ, Crain C, Heath VL, Savelkoul HF, O'Garra A: 1alpha,25Dihydroxyvitamin $\mathrm{d} 3$ has a direct effect on naive CD4(+) T cells to enhance the development of Th2 cells. J Immunol 2001, 167:4974-4980.

60. Yu S, Cantorna MT: Epigenetic reduction in invariant NKT cells following in utero vitamin D deficiency in mice. J Immunol 2011, 186:1384-1390.

61. Smolders J, Thewissen M, Peelen E, Menheere P, Tervaert JWC, Damoiseaux J, Hupperts R: Vitamin D status is positively correlated with regulatory $T$ cell function in patients with multiple sclerosis. PLoS One 2009, 4:e6635.

62. Döring A, Paul F, Dörr J: Vitamin D and multiple sclerosis: the role for risk of disease and treatment. Nervenarzt 2012. doi:10.1007/s00115-012-3645-z.

63. Eyles DW, Smith S, Kinobe R, Hewison M, McGrath JJ: Distribution of the vitamin $D$ receptor and 1 alpha-hydroxylase in human brain. $J$ Chem Neuroanat 2005, 29:21-30.

64. Garcion E, Wion-Barbot N, Montero-Menei CN, Berger F, Wion D: New clues about vitamin D functions in the nervous system. Trends Endocrinol Metab 2002, 13:100-105.

65. de Abreu DAF, Eyles D, Féron F: Vitamin D, a neuro-immunomodulator: implications for neurodegenerative and autoimmune diseases. Psychoneuroendocrinology 2009, 34(Suppl 1):S265-S277.

66. Dyment DA, Sadovnick AD, Ebers GC, Sadnovich AD: Genetics of multiple sclerosis. Hum Mol Genet 1997, 6:1693-1698

67. Sadovnick AD: Genetic background of multiple sclerosis. Autoimmun Rev 2012, 11:163-166.

68. Ramagopalan SV, Maugeri NJ, Handunnetthi L, Lincoln MR, Orton S-M, Dyment DA, Deluca GC, Herrera BM, Chao MJ, Sadovnick AD, Ebers GC, Knight JC: Expression of the multiple sclerosis-associated MHC class II Allele HLA-DRB1*1501 is regulated by vitamin D. PLoS Genet 2009, 5:e1000369.
69. Ramagopalan SV, Dyment DA, Cader MZ, Morrison KM, Disanto G, Morahan JM, Berlanga-Taylor AJ, Handel A, De Luca GC, Sadovnick AD, Lepage P, Montpetit A, Ebers GC: Rare variants in the CYP27B1 gene are associated with multiple sclerosis. Ann Neurol 2011, 70:881-886.

70. Torkildsen $\varnothing$, Knappskog PM, Nyland HI, Myhr KM: Vitamin D-dependent rickets as a possible risk factor for multiple sclerosis. Arch Neurol 2008, 65:809-811.

71. Ramagopalan SV, Hanwell HEC, Giovannoni G, Knappskog PM, Nyland HI Myhr K-M, Ebers GC, Torkildsen O: Vitamin D-dependent rickets, HLADRB1, and the risk of multiple sclerosis. Arch Neurol 2010, 67:1034-1035.

72. Lemire JM, Archer DC: 1,25-dihydroxyvitamin D3 prevents the in vivo induction of murine experimental autoimmune encephalomyelitis. J Clin Invest 1991, 87:1103-1107.

73. Cantorna MT, Hayes CE, DeLuca HF: 1,25-Dihydroxyvitamin D3 reversibly blocks the progression of relapsing encephalomyelitis, a model of multiple sclerosis. Proc Natl Acad Sci USA 1996, 93:7861-7864.

74. Pedersen LB, Nashold FE, Spach KM, Hayes CE: 1,25-dihydroxyvitamin D3 reverses experimental autoimmune encephalomyelitis by inhibiting chemokine synthesis and monocyte trafficking. J Neurosci Res 2007, 85:2480-2490

75. Spach KM, Hayes CE: Vitamin D3 confers protection from autoimmune encephalomyelitis only in female mice. J Immunol 2005, 175:4119-4126.

76. Becklund BR, Severson KS, Vang SV, DeLuca HF: UV radiation suppresses experimental autoimmune encephalomyelitis independent of vitamin D production. Proc Natl Acad Sci USA 2010, 107:6418-6423.

77. Wergeland S, Torkildsen O, Myhr KM, Aksnes L, Mørk SJ, Bø L: Dietary vitamin D3 supplements reduce demyelination in the cuprizone model. PLoS One 2011, 6:e26262.

78. Acheson ED, Bachrach CA, Wright FM: Some comments on the relationship of the distribution of multiple sclerosis to latitude, solar radiation, and other variables. Acta Psychiatr Scand Suppl 1960, 35:132-147.

79. Kurtzke JF: An evaluation of the geographic distribution of multiple sclerosis. Acta Neurol Scand 1966, 42(Suppl 19):91.

80. Swank RL, Lerstad O, Strom A, Backer J: Multiple sclerosis in rural Norway its geographic and occupational incidence in relation to nutrition. N Engl J Med 1952, 246:722-728.

81. Kurtzke JF, Beebe GW, Norman JE Jr: Epidemiology of multiple sclerosis in US veterans: III. Migration and the risk of MS. Neurology 1985, 35:672-678.

82. Willer CJ, Dyment DA, Sadovnick AD, Rothwell PM, Murray TJ, Ebers GC: Timing of birth and risk of multiple sclerosis: population based study. BMJ 2005, 330:120.

83. 'Sotgiu S, Pugliatti M, Sotgiu MA, Fois ML, Arru G, Sanna A, Rosati G: Seasonal fluctuation of multiple sclerosis births in Sardinia. J Neuro/ 2006, 253:38-44.

84. Salzer J, Svenningsson A, Sundström P: Season of birth and multiple sclerosis in Sweden. Acta Neurol Scand 2010, 122:70-73.

85. Dobson R, Giovannoni G, Ramagopalan S: The month of birth effect in multiple sclerosis: systematic review, meta-analysis and effect of latitude. J Neurol Neurosurg Psychiatr 2012, doi:10.1136/jnnn-2012-303934.

86. Van der Mei IAF, Ponsonby AL, Dwyer T, Blizzard L, Simmons R, Taylor BV, Butzkueven $\mathrm{H}$, Kilpatrick T: Past exposure to sun, skin phenotype, and risk of multiple sclerosis: case-control study. BMJ 2003, 327:316.

87. Islam T, Gauderman WJ, Cozen W, Mack TM: Childhood sun exposure influences risk of multiple sclerosis in monozygotic twins. Neurology 2007, 69:381-388.

88. Dalmay F, Bhalla D, Nicoletti A, Cabrera-Gomez JA, Cabre P, Ruiz F, DruetCabanac M, Dumas M, Preux PM: Multiple sclerosis and solar exposure before the age of 15 years: case-control study in Cuba, Martinique and Sicily. Mult Scler 2010, 16:899-908.

89. Kampman MT, Wilsgaard T, Mellgren SI: Outdoor activities and diet in childhood and adolescence relate to MS risk above the Arctic Circle. J Neurol 2007, 254:471-477.

90. McDowell TY, Amr S, Culpepper WJ, Langenberg P, Royal W, Bever C, Bradham DD: Sun exposure, vitamin D and age at disease onset in relapsing multiple sclerosis. Neuroepidemiology 2011, 36:39-45.

91. McDowell TY, Amr S, Culpepper WJ, Langenberg P, Royal W, Bever C, Bradham DD: Sun exposure, vitamin D intake and progression to disability among veterans with progressive multiple sclerosis. Neuroepidemiology 2011, 37:52-57.

92. Van der Mei IAF, Blizzard L, Ponsonby AL, Dwyer T: Validity and reliability of adult recall of past sun exposure in a case-control study of multiple sclerosis. Cancer Epidemiol Biomarkers Prev 2006, 15:1538-1544. 
93. Lucas RM, Ponsonby AL, Dear K, Valery PC, Pender MP, Taylor BV, Kilpatrick TJ, Dwyer T, Coulthard A, Chapman C, Van der Mei I, Williams D, McMichael AJ: Sun exposure and vitamin $\mathrm{D}$ are independent risk factors for CNS demyelination. Neurology 2011, 76:540-548.

94. Hart PH, Gorman S, Finlay-Jones JJ: Modulation of the immune system by UV radiation: more than just the effects of vitamin D? Nat Rev Immunol 2011, 11:584-596.

95. Jin Y, De Pedro-Cuesta J, Söderström M, Stawiarz L, Link H: Seasonal patterns in optic neuritis and multiple sclerosis: a meta-analysis. J Neurol Sci 2000, 181:56-64.

96. Handel AE, Disanto G, Jarvis L, McLaughlin R, Fries A, Ebers GC, Ramagopalan SV: Seasonality of admissions with multiple sclerosis in Scotland. Eur J Neurol 2011, 18:1109-1111.

97. Meier DS, Balashov KE, Healy B, Weiner HL, Guttmann CRG: Seasonal prevalence of MS disease activity. Neurology 2010, 75:799-806.

98. Auer DP, Schumann EM, Kümpfel T, Gössl C, Trenkwalder C: Seasonal fluctuations of gadolinium-enhancing magnetic resonance imaging lesions in multiple sclerosis. Ann Neurol 2000, 47:276-277.

99. Tremlett H, Van der Mei IAF, Pittas F, Blizzard L, Paley G, Mesaros D, Woodbaker R, Nunez M, Dwyer T, Taylor BV, Ponsonby AL: Monthly ambient sunlight, infections and relapse rates in multiple sclerosis. Neuroepidemiology 2008 31:271-279.

100. Mirzaei F, Michels KB, Munger K, O'Reilly E, Chitnis T, Forman MR, Giovannucci E, Rosner B, Ascherio A: Gestational vitamin D and the risk of multiple sclerosis in offspring. Ann Neurol 2011, 70:30-40.

101. Banwell B, Bar-Or A, Arnold DL, Sadovnick D, Narayanan S, McGowan M, O'Mahony J, Magalhaes S, Hanwell H, Vieth R, Tellier R, Vincent T, Disanto G, Ebers G, Wambera K, Connolly MB, Yager J, Mah JK, Booth F, Sebire G, Callen D, Meaney B, Dilenge ME, Lortie A, Pohl D, Doja A, Venketaswaran S, Levin S, Macdonald EA, Meek D, et al: Clinical, environmental, and genetic determinants of multiple sclerosis in children with acute demyelination: a prospective national cohort study. Lancet Neurol 2011, 10:436-445.

102. Munger KL, Levin LI, Hollis BW, Howard NS, Ascherio A: Serum 25hydroxyvitamin D levels and risk of multiple sclerosis. JAMA 2006, 296:2832-2838.

103. Munger KL, Zhang SM, O'Reilly E, Hernán MA, Olek MJ, Willett WC, Ascherio A: Vitamin D intake and incidence of multiple sclerosis. Neurology 2004, 62:60-65.

104. Soilu-Hänninen M, Airas L, Mononen I, Heikkilä A, Viljanen M, Hänninen A: 25-Hydroxyvitamin D levels in serum at the onset of multiple sclerosis. Mult Scler 2005, 11:266-271

105. Simpson S Jr, Taylor B, Blizzard L, Ponsonby AL, Pittas F, Tremlett H, Dwyer T, Gies $P$, Van der Mei I: Higher 25-hydroxyvitamin D is associated with lower relapse risk in multiple sclerosis. Ann Neurol 2010, 68:193-203.

106. Pierrot-Deseilligny C, Rivaud-Péchoux S, Clerson P, De Paz R, Souberbielle $J C$ : Relationship between $25-\mathrm{OH}-\mathrm{D}$ serum level and relapse rate in multiple sclerosis patients before and after vitamin $D$ supplementation. Ther Adv Neurol Disord 2012, 5:187-198.

107. Runia TF, Hop WCJ, De Rijke YB, Buljevac D, Hintzen RQ: Lower serum vitamin $D$ levels are associated with a higher relapse risk in multiple sclerosis. Neurology 2012, 79:261-266.

108. Mowry EM, Krupp LB, Milazzo M, Chabas D, Strober JB, Belman AL, McDonald JC, Oksenberg JR, Bacchetti P, Waubant E: Vitamin D status is associated with relapse rate in pediatric-onset multiple sclerosis. Ann Neurol 2010, 67:618-624

109. Mowry EM, Waubant E, McCulloch CE, Okuda DT, Evangelista AA, Lincoln RR, Gourraud P-A, Brenneman D, Owen MC, Qualley P, Bucci M, Hauser SL, Pelletier D: Vitamin D status predicts new brain magnetic resonance imaging activity in multiple sclerosis. Ann Neurol 2012, 72:234-240.

110. Løken-Amsrud KI, Holmøy T, Bakke SJ, Beiske AG, Bjerve KS, Bjørnarå BT, Hovdal H, Lilleås F, Midgard R, Pedersen T, Benth JS, Sandvik L, Torkildsen O, Wergeland S, Myhr K-M: Vitamin D and disease activity in multiple sclerosis before and during interferon- $\beta$ treatment. Neurology 2012, 79:267-273.

111. Holmøy T, Moen SM, Gundersen TA, Holick MF, Fainardi E, Castellazzi M, Casetta I: 25-hydroxyvitamin D in cerebrospinal fluid during relapse and remission of multiple sclerosis. Mult Scler 2009, 15:1280-1285.

112. Goldberg P, Fleming MC, Picard EH: Multiple sclerosis: decreased relapse rate through dietary supplementation with calcium, magnesium and vitamin D. Med Hypotheses 1986, 21:193-200.
113. Kimball SM, Ursell MR, O'Connor P, Vieth R: Safety of vitamin D3 in adults with multiple sclerosis. Am J Clin Nutr 2007, 86:645-651.

114. Burton JM, Kimball S, Vieth R, Bar-Or A, Dosch H-M, Cheung R, Gagne D, D'Souza C, Ursell M, O'Connor P: A phase I/II dose-escalation trial of vitamin D3 and calcium in multiple sclerosis. Neurology 2010, 74:1852-1859.

115. Mahon BD, Gordon SA, Cruz J, Cosman F, Cantorna MT: Cytokine profile in patients with multiple sclerosis following vitamin D supplementation. J Neuroimmunol 2003, 134:128-132.

116. Stein MS, Liu Y, Gray OM, Baker JE, Kolbe SC, Ditchfield MR, Egan GF, Mitchell PJ, Harrison LC, Butzkueven $\mathrm{H}$, Kilpatrick TJ: A randomized trial of high-dose vitamin D2 in relapsing-remitting multiple sclerosis. Neurology 2011, 77:1611-1618.

117. Grimaldi L, Barkhof F, Beelke M, Burton J, Holmoy T, Hupperts R, Killestein J, Rieckmann P, Schluep M, Smolders J: A randomized trial of high-dose vitamin D2 in relapsing-remitting multiple sclerosis. Neurology 2012, 78:841.

118. Shaygannejad V, Janghorbani M, Ashtari F, Dehghan H: Effects of adjunct low-dose vitamin $\mathrm{d}$ on relapsing-remitting multiple sclerosis progression: preliminary findings of a randomized placebo-controlled trial. Mult Scler Int 2012, 2012:452541

119. Soilu-Hänninen M, Aivo J, Lindström B-M, Elovaara I, Sumelahti M-L, Färkkilä M, Tienari P, Atula S, Sarasoja T, Herrala L, Keskinarkaus I, Kruger J, Kallio T, Rocca MA, Filippi M: A randomised, double blind, placebo controlled trial with vitamin D3 as an add on treatment to interferon $\beta-1 \mathrm{~b}$ in patients with multiple sclerosis. J Neurol Neurosurg Psychiatry 2012, 83:565-571.

120. Aivo J, Lindsröm B-M, Soilu-Hänninen M: A randomised, double-blind, placebo-controlled trial with vitamin D3 in MS: subgroup analysis of patients with baseline disease activity despite interferon treatment. Mult Scler Int 2012, 2012:802796.

121. Kampman MT, Steffensen LH, Mellgren SI, Jørgensen L: Effect of vitamin D3 supplementation on relapses, disease progression and measures of function in persons with multiple sclerosis: exploratory outcomes from a double-blind randomised controlled trial. Mult Scler 2012, 18:1144-1151.

122. Smolders J, Hupperts R, Barkhof F, Grimaldi LME, Holmoy T, Killestein J, Rieckmann P, Schluep M, Vieth R, Hostalek U, Ghazi-Visser L, Beelke M: Efficacy of vitamin D(3) as add-on therapy in patients with relapsingremitting multiple sclerosis receiving subcutaneous interferon beta-1a: a Phase II, multicenter, double-blind, randomized, placebo-controlled trial. J Neurol Sci 2011, 311:44-49.

123. Dörr J, Ohlraun S, Skarabis H, Paul F: Efficacy of Vitamin D Supplementation in Multiple Sclerosis (EVIDIMS Trial): study protocol for a randomized controlled trial. Trials 2012, 13:15

124. Marcus JF, Shalev SM, Harris CA, Goodin DS, Josephson SA: Severe hypercalcemia following vitamin $D$ supplementation in a patient with multiple sclerosis: a note of caution. Arch Neurol 2012, 69:129-132.

125. Wingerchuk DM, Lesaux J, Rice GPA, Kremenchutzky M, Ebers GC: A pilot study of oral calcitriol (1,25-dihydroxyvitamin D3) for relapsing-remitting multiple sclerosis. J Neurol Neurosurg Psychiatr 2005, 76:1294-1296.

126. Jagannath VA, Fedorowicz Z, Asokan GV, Robak EW, Whamond L: Vitamin D for the management of multiple sclerosis. Cochrane Database Syst Rev 2010, 12:CD008422.

127. Hathcock JN, Shao A, Vieth R, Heaney R: Risk assessment for vitamin D. Am J Clin Nutr 2007, 85:6-18.

128. Golubnitschaja O, Costigliola V, EPMA: General report \& recommendations in predictive, preventive and personalised medicine 2012: white paper of the European Association for Predictive, Preventive and Personalised Medicine. EPMA J 2012, 3:14

doi:10.1186/1878-5085-4-4

Cite this article as: Dörr et al:: Can we prevent or treat multiple sclerosis by individualised vitamin D supply?. The EPMA Journal 2013 4:4. 